\title{
Effectiveness of radial artery-based multiarterial coronary artery bypass grafting: Role of body habitus
}

Thomas A. Schwann, MD, ${ }^{a, c}$ Paul S. Ramia, MD, ${ }^{b}$ Joseph R. Habib, BS, ${ }^{b}$ Milo C. Engoren, MD, ${ }^{d}$ Mark R. Bonnell, MD, ${ }^{a}$ and Robert H. Habib, $\mathrm{PhD}^{\mathrm{e}}$

\section{ABSTRACT}

Background: The multiarterial grafting survival advantage noted in the overall population undergoing coronary artery bypass grafting is not well defined in the obese. We investigated the early to late survival effects of the radial artery in left internal thoracic artery-based multiarterial bypass grafting (radial arterymultiarterial bypass grafting) versus single arterial bypass grafting (left internal thoracic artery-single arterial bypass grafting) in obese patients.

Methods: We analyzed 15-year Kaplan-Meier survival in 6102 patients receiving primary, left internal thoracic artery-based coronary artery bypass grafting with 2 or more grafts divided into body mass index groups: nonobese $\left(<30 \mathrm{~kg} / \mathrm{m}^{2}\right)$ and all-obese, comprised of mildly obese $\left(30-35 \mathrm{~kg} / \mathrm{m}^{2}\right)$ and morbidly obese $\left(>35 \mathrm{~kg} / \mathrm{m}^{2}\right.$ ). Risk-adjusted hazard ratios (HRs) and $95 \%$ confidence intervals (CIs) of radial artery-multiarterial bypass grafting versus left internal thoracic artery-single arterial bypass grafting were derived via Cox regression and applied separately for early ( $<0.5$ years), intermediate $(0.5-5$ years $)$, and late $(5-15$ years) follow-up in each body mass index cohort. Propensity score matching between radial artery-multiarterial bypass grafting and left internal thoracic artery-single arterial bypass grafting cohorts within the body mass index groups was performed as a corroborating analysis.

Results: Radial artery-multiarterial bypass grafting was more frequently used in obese patients who were younger (62 \pm 10 years; mild/morbid: $45.4 \% / 54.4 \%$ radial artery-multiarterial bypass grafting) compared with nonobese patients $(66 \pm 10$ years; $37.4 \%$ radial artery-multiarterial bypass grafting). Unadjusted 15-year survival was significantly better for radial artery-multiarterial bypass grafting in all body mass index groups. Multivariate analysis showed a survival benefit of radial artery-multiarterial bypass grafting over the entire 0- to 15year study period in the all-obese cohort (HR, 0.85; 95\% CI, 0.74-0.98) and was more pronounced in the mildly obese (HR, $0.79 ; 95 \% \mathrm{CI}, 0.66-0.96)$ versus morbidly obese (HR, $0.88 ; 95 \%$ CI, 0.69-1.13). The radial artery-multiarterial bypass grafting survival benefit was realized between 0.5 and 5 years postoperatively and was comparable for all-obese (HR, 0.69; 95\% CI, 0.51-0.94) and nonobese (HR, 0.68; 95\% CI, 0.52-0.88) groups. Propensity score matching was confirmatory.

Conclusions: Radial artery-multiarterial bypass grafting confers a long-term survival advantage in both obese and nonobese patients. ( $\mathrm{J}$ Thorac Cardiovasc Surg 2018;156:43-51)

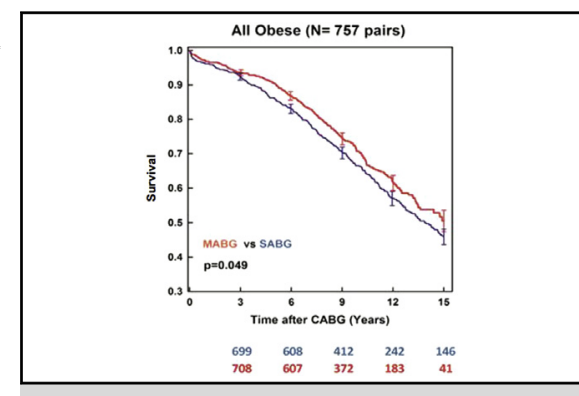

The 15-year survival in propensity-matched obese patients receiving MABG (red) versus SABG (blue).

\section{Central Message}

RA-MABG improves long-term outcomes in obese patients compared with LITA-SABG and thus should be strongly considered as the grafting strategy of choice by the Heart Team in obese patients.

\section{Perspective}

In light of the worldwide obesity epidemic, the obese patient undergoing CABG is an increasingly common challenge for the cardiac surgeon. Whether the multiarterial survival advantage is also found in obese patients is not well defined and warrants further analysis.

See Editorial Commentary page 52.

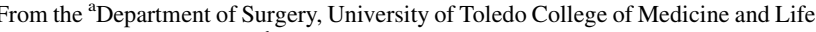
Sciences, Toledo, Ohio; ${ }^{\mathrm{b}}$ Department of Internal Medicine, Outcomes Research Unit, American University of Beirut, Beirut, Lebanon; ${ }^{\mathrm{c}}$ Mercy Saint Vincent Medical Center, Toledo, Ohio; ${ }^{\mathrm{d}}$ Department of Anesthesiology, University of Michigan, Ann Arbor, Mich; and ${ }^{\mathrm{e} S}$ Society of Thoracic Surgeons Research Center, Chicago, Ill.

Research funded by Departmental and Institutional funds.
}

Received for publication Aug 29, 2017; revisions received Jan 9, 2018; accepted for publication Feb 4, 2018; available ahead of print March 31, 2018.

Address for reprints: Thomas A. Schwann, MD, University of Toledo College of Medicine and Life Sciences, 3000 Arlington Ave, Toledo, OH 43614 (E-mail: Thomas.schwann@utoledo.edu).

$0022-5223 / \$ 36.00$

Copyright (c) 2018 by The American Association for Thoracic Surgery

https://doi.org/10.1016/j.jtcvs.2018.02.085 


$$
\begin{aligned}
& \text { Abbreviations and Acronyms } \\
& \text { BITA }=\text { bilateral internal thoracic artery } \\
& \text { BMI }=\text { body mass index } \\
& \text { CABG }=\text { coronary artery bypass grafting } \\
& \text { CI }=\text { confidence interval } \\
& \text { HR }=\text { hazard ratio } \\
& \text { LITA }=\text { left internal thoracic artery } \\
& \text { MABG }=\text { multiarterial bypass grafting } \\
& \text { NNT }=\text { number needed to treat } \\
& \text { RA }=\text { radial artery } \\
& \text { RI }=\text { revascularization index } \\
& \text { SABG }=\text { single arterial bypass grafting } \\
& \text { SVG }=\text { saphenous vein graft }
\end{aligned}
$$

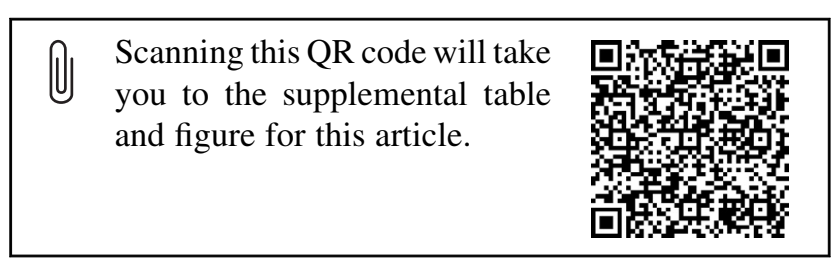

Obesity has reached epidemic proportions. The World Health Organization estimates that obesity doubled within the last 3 decades, with approximately $70 \%$ of American adults being overweight or obese compared with less than $25 \% 40$ years ago. ${ }^{1-3}$ Obesity is a well-known risk factor for coronary atherosclerosis and other cardiovascular conditions, such as hypertension, heart failure, peripheral vascular disease, and atrial fibrillation. ${ }^{4,5}$ Obesity is also an independent predictor of long-term morbidity and mortality driven by its well-established association with the cardiometabolic syndrome and likely through yet unrecognized mechanisms. ${ }^{6}$ Not surprisingly, obesity is increasingly common among patients undergoing coronary artery bypass grafting (CABG) with $39 \%$ to $51 \%$ of patients undergoing CABG who are in the 2004-2014 Society of Thoracic Surgeons Database being obese.

The existing data on the impact of obesity on CABG outcomes are conflicting with some investigators reporting improved, equivalent, or worse outcomes in obese patients ${ }^{8-13}$ compared with nonobese patients. These studies overwhelmingly focus on patients undergoing left internal thoracic artery (LITA)-based single arterial bypass grafting (SABG), and there is a paucity of data on whether multiarterial bypass grafting (MABG) is associated with a similar survival advantage that has been repeatedly described in the overall CABG population. ${ }^{14-19}$ Because postoperative survival is linked to coronary arterial graft durability, the enhanced inflammatory and prothrombotic states characteristic of the obese ${ }^{6}$ could more negatively affect arterial versus venous graft durability and thus mitigate the survival benefit of MABG. Benedetto and colleagues ${ }^{20}$ noted improved survival only among obese patients undergoing bilateral internal thoracic artery (BITA) grafting but reported equivalent survival when the radial artery (RA) was used as the second arterial graft in conjunction with the LITA. ${ }^{21}$

Within this context, we compared the long-term survival of obese and nonobese patients undergoing RA-MABG and traditional LITA-SABG in an attempt to define the superior grafting strategy in the increasingly commonly encountered obese patients undergoing $\mathrm{CABG}$.

\section{MATERIALS AND METHODS}

This investigation is a retrospective analysis of prospective cardiac surgery experiences at 2 Ohio centers (1994-2007). Data were collected in accordance with the Society of Thoracic Surgeons National Adult Cardiac Surgery Database standards. Study data were restricted to those available in the database with no additional review of hospital records or patient contact. This study received institutional review board approval from both participating institutions, and the need for informed consent was waived.

\section{Patients and Study Groups}

The study group consisted of patients receiving isolated, primary LITACABG with 2 or more grafts between 1994 and 2007. Patients were excluded in case of concomitant surgery, single graft, no LITA, BITA grafting, salvage surgery, preoperative renal failure, and reoperations. Patients with preoperative renal failure were excluded because of poor prognosis and their ineligibility for RA-MABG because of the need for RA-based dialysis access. Patients were stratified into body habitus groups based on body mass index (BMI): nonobese (BMI $<30 \mathrm{~kg} / \mathrm{m}^{2}$ ) and all-obese (BMI $\geq 30 \mathrm{~kg} / \mathrm{m}^{2}$ ), which comprised the mildly obese (BMI $30-35 \mathrm{~kg} /$ $\mathrm{m}^{2}$ ) and the morbidly obese (BMI $>35 \mathrm{~kg} / \mathrm{m}^{2}$ ). Each group was divided according to the specific grafting strategy used: RA-MABG (LITA/ $\mathrm{RA} \pm$ saphenous vein graft $[\mathrm{SVG}]$ ) or LITA-SABG (LITA/SVG). The operative technique and perioperative management have been described. ${ }^{15,19,22}$ Cardiopulmonary bypass (97\%) and aortocoronary grafting $(99 \%)$ were used in the majority of patients.

\section{Surgery and Follow-up}

The primary outcome measure was all-cause mortality across the BMI groups for RA-MABG versus LITA-SABG with secondary analysis focusing on the time frame of the mortality comparison. Mortality data were secured from recurrent (semiannual) queries of the US Social Security Death Index database (http://ssdi.genealogy.rootsweb.com; last checked November 2011). Mortality data were obtained from the 19942013 Ohio death index for verification and exclusively for determining mortality after November 2011.

\section{Statistical Analysis}

Continuous variables were expressed as mean \pm standard deviation and compared using the independent $t$ test or Mann-Whitney $U$ test based on normality. Categoric variables were expressed as counts (percentages) and compared by the chi-square test. Fifteen-year survival, based on all-cause mortality (inclusive of acute perioperative mortality), was derived via Kaplan-Meier analysis and compared for RA-MABG versus LITA-SABG cohorts across the BMI groups (log rank test) and was performed on all patients (unadjusted) as well for within each BMI group and MABG and SABG propensity-matched subcohorts. Comparisons were also done for mild and morbid obese patients combined, which comprised the obese group.

Comparative outcomes in grafting subcohorts and body habitus groups were confounded by significant demographic and risk factor differences (Table 1). Our primary risk adjustment to reduce such confounding was 
TABLE 1. Demographic, comorbidity, and operative data in patients receiving single arterial bypass graft versus multiarterial bypass graft stratified to nonobese, mild obese, and morbid obese

\begin{tabular}{|c|c|c|c|c|c|c|c|c|c|}
\hline \multirow{2}{*}{ Patient factors } & \multicolumn{3}{|c|}{ Nonobese $(\mathbf{N}=3566)$} & \multicolumn{3}{|c|}{ Mild obese $(N=1591)$} & \multicolumn{3}{|c|}{ Morbid obese $(\mathrm{N}=\mathbf{9 4 5})$} \\
\hline & \multirow{2}{*}{$\begin{array}{c}\text { SABG } \\
(\mathrm{N}=\mathbf{2 2 3 2}) \\
\text { Mean } \pm \text { SD }\end{array}$} & \multirow{2}{*}{$\begin{array}{c}\text { MABG } \\
(\mathbf{N}=\mathbf{1 3 3 4}) \\
\text { Mean } \pm \text { SD }\end{array}$} & \multirow[b]{2}{*}{$\%$ Diff } & \multirow{2}{*}{$\begin{array}{c}\text { SABG } \\
(\mathbf{N}=\mathbf{8 6 9}) \\
\text { Mean } \pm \text { SD }\end{array}$} & \multirow{2}{*}{$\begin{array}{c}\text { MABG } \\
(\mathrm{N}=722) \\
\text { Mean } \pm \text { SD }\end{array}$} & \multirow[b]{2}{*}{$\%$ Diff } & \multirow{2}{*}{$\begin{array}{c}\text { SABG } \\
(\mathbf{N}=431) \\
\text { Mean } \pm \text { SD }\end{array}$} & \multirow{2}{*}{$\begin{array}{c}\text { MABG } \\
(\mathrm{N}=\mathbf{5 1 4}) \\
\text { Mean } \pm \text { SD }\end{array}$} & \multirow[b]{2}{*}{$\%$ Diff } \\
\hline Continuous & & & & & & & & & \\
\hline Age (y) & $67.3 \pm 10.2$ & $2 \quad 63.2 \pm 10.4$ & 40.2 & $64.8 \pm 9.6$ & $61.0 \pm 9.7$ & 39.3 & $61.4 \pm 9.8$ & $58.7 \pm 9.3$ & 23.1 \\
\hline $\operatorname{BSA}\left(\mathrm{m}^{2}\right)$ & $1.89 \pm 0.20$ & $\begin{array}{ll}0 & 1.95 \pm 0.19\end{array}$ & 30.8 & $2.10 \pm 0.19$ & $2.20 \pm 0.18$ & 31.2 & $2.27 \pm 0.20$ & $2.34 \pm 0.20$ & 22.4 \\
\hline Ejection fraction & $49.0 \pm 11$. & $4 \quad 49.3 \pm 10.3$ & 2.7 & $49.3 \pm 11.3$ & $49.2 \pm 10.6$ & 1.4 & $49.2 \pm 11.5$ & $49.0 \pm 10.1$ & 1.1 \\
\hline Perfusion time (min) & $79 \pm 33$ & $82 \pm 31$ & 9.6 & $81 \pm 30$ & $84 \pm 32$ & 10.8 & $81 \pm 36$ & $88 \pm 30$ & 16.6 \\
\hline Crossclamp time (min) & $47 \pm 20$ & $53 \pm 22$ & 24.3 & $48 \pm 20$ & $53 \pm 22$ & 21.3 & $49 \pm 23$ & $56 \pm 22$ & 24.8 \\
\hline RI & $0.53 \pm 0.71$ & $1 \quad 0.80 \pm 0.73$ & 37.8 & $0.52 \pm 0.72$ & $0.78 \pm 0.76$ & 34.8 & $0.51 \pm 0.70$ & $0.80 \pm 0.80$ & 31.9 \\
\hline No. of grafts & $3.23 \pm 0.82$ & $2 \quad 3.62 \pm 0.89$ & 40.0 & $3.26 \pm 0.85$ & $3.62 \pm 0.95$ & 39.9 & $3.23 \pm 0.90$ & $3.65 \pm 0.90$ & 39.2 \\
\hline $\begin{array}{l}\text { No. of distal arterial } \\
\text { anastamoses }\end{array}$ & $1 \pm 0$ & $2.26 \pm 0.54$ & 332.6 & $1 \pm 0$ & $2.27 \pm 0.54$ & 331.0 & $1 \pm 0$ & $2.30 \pm 0.60$ & 321.2 \\
\hline No. of distal vein anastamose & es $\quad 2.28 \pm 0.82$ & $2 \quad 1.36 \pm 0.86$ & 108.9 & $2.26 \pm 0.85$ & $1.34 \pm 0.91$ & 103.9 & $2.23 \pm 0.90$ & $1.35 \pm 0.90$ & 82.3 \\
\hline Year of surgery (1-14) & $5.89 \pm 3.6$ & $4 \quad 8.65 \pm 2.91$ & 83.8 & $5.99 \pm 3.75$ & $8.45 \pm 2.97$ & 73.0 & $6.57 \pm 3.76$ & $8.98 \pm 2.89$ & 71.9 \\
\hline Categoric & Counts $(\%)$ & Counts $(\%)$ & $\%$ Diff & Counts $(\%)$ & Counts $(\%)$ & $\%$ Diff & Counts $(\%)$ & Counts $(\%)$ & $\%$ Diff \\
\hline Male & $1510(67.7)$ & $1050(78.7)$ & 25.2 & $564(64.9)$ & $558(77.3)$ & 26.9 & $227(52.7)$ & $317(61.7)$ & 17.3 \\
\hline Smoking & $1447(64.8)$ & $935(70.1)$ & 11.2 & $559(64.3)$ & $477(66.1)$ & 3.6 & $287(66.6)$ & $328(63.8)$ & 5.6 \\
\hline Diabetes & $641(28.7)$ & $348(26.1)$ & 5.9 & $381(43.8)$ & $294(40.7)$ & 6.0 & $220(51.0)$ & $282(54.9)$ & 7.2 \\
\hline Insulin dependence & $216(9.7)$ & $89(6.7)$ & 11.0 & $133(15.3)$ & $76(10.5)$ & 15.0 & $88(20.4)$ & $94(18.3)$ & 5.5 \\
\hline Hypercholesterolemia & $1425(63.8)$ & $981(73.5)$ & 21.0 & $604(69.5)$ & $554(76.7)$ & 15.9 & $313(72.6)$ & $403(78.4)$ & 13.3 \\
\hline Hypertension & $1745(78.2)$ & $1043(78.2)$ & 0.0 & $752(86.5)$ & $597(82.7)$ & 11.2 & $372(86.3)$ & $447(87.0)$ & 2.0 \\
\hline Peripheral vascular disease & $411(18.4)$ & $160(12.0)$ & 18.0 & $149(17.1)$ & $68(9.4)$ & 23.7 & $67(15.5)$ & $49(9.5)$ & 19.0 \\
\hline Cerebrovascular disease & $685(30.7)$ & $224(16.8)$ & 33.1 & 249 (28.7) & $116(16.1)$ & 30.2 & $105(24.4)$ & $73(14.2)$ & 26.1 \\
\hline Cerebrovascular accident & $197(8.8)$ & $77(5.8)$ & 11.8 & $76(8.7)$ & $41(5.7)$ & 12.8 & $31(7.2)$ & $26(5.1)$ & 9.9 \\
\hline Chronic lung disease & $491(22.0)$ & $223(16.7)$ & 13.4 & $158(18.2)$ & $107(14.8)$ & 9.3 & $89(20.6)$ & $106(20.6)$ & 0.1 \\
\hline Myocardial infarction & $1292(57.9)$ & $715(53.6)$ & 8.6 & $504(58.0)$ & $381(52.8)$ & 9.9 & $257(59.6)$ & $250(48.6)$ & 21.0 \\
\hline Congestive heart failure & 259 (11.6) & $75(5.6)$ & 21.4 & $109(12.5)$ & $61(8.4)$ & 14.4 & $65(15.1)$ & $65(12.6)$ & 7.4 \\
\hline 2-vessel disease & 459 (20.6) & $237(17.8)$ & 7.1 & $207(23.8)$ & $129(17.9)$ & 14.6 & $105(24.4)$ & $87(16.9)$ & 18.5 \\
\hline 3-vessel disease & $1713(76.7)$ & $1078(80.8)$ & 9.9 & $648(74.6)$ & $586(81.2)$ & 15.9 & $314(72.9)$ & $423(82.3)$ & 22.6 \\
\hline Multivessel disease & $2172(97.3)$ & 1315 (98.6) & 8.9 & $855(98.4)$ & $715(99.0)$ & 6.4 & $419(97.2)$ & $510(99.2)$ & 16.5 \\
\hline Left main disease & $526(23.6)$ & $312(23.4)$ & 0.4 & $178(20.5)$ & $157(21.7)$ & 3.0 & $76(17.6)$ & $103(20.0)$ & 6.3 \\
\hline \multicolumn{10}{|l|}{ PCI } \\
\hline Balloon angioplasty & $184(8.2)$ & $93(7.0)$ & 4.8 & $87(10.0)$ & $48(6.6)$ & 13.3 & 50 (11.6) & $24(4.7)$ & 26.9 \\
\hline Stent & $188(8.4)$ & $169(12.7)$ & 13.9 & $90(10.4)$ & 93 (12.9) & 8.6 & $49(11.4)$ & $67(13.0)$ & 5.5 \\
\hline Arrhythmia & $283(12.7)$ & $76(5.7)$ & 24.3 & $110(12.7)$ & $29(4.0)$ & 33.0 & $36(8.4)$ & $39(7.6)$ & 3.1 \\
\hline Unstable angina & $779(34.9)$ & $392(29.4)$ & 11.8 & $283(32.6)$ & $239(33.1)$ & 1.1 & $156(36.2)$ & $166(32.3)$ & 7.9 \\
\hline Emergency & $146(6.5)$ & $69(5.2)$ & 5.8 & $55(6.3)$ & $34(4.7)$ & 8.0 & $35(8.1)$ & $21(4.1)$ & 18.3 \\
\hline $\mathrm{CABG}+$ other surgery & $232(10.4)$ & $116(8.7)$ & 5.8 & $81(9.3)$ & $72(10.0)$ & 2.5 & $42(9.7)$ & 39 (7.6) & 8.3 \\
\hline \multicolumn{10}{|l|}{ NYHA class } \\
\hline 1 & $86(3.9)$ & $113(8.5)$ & 19.3 & $43(4.9)$ & $58(8.0)$ & 14.9 & $15(3.5)$ & $32(6.2)$ & 16.1 \\
\hline 2 & 311 (13.9) & 288 (21.6) & 20.1 & 93 (10.7) & 156 (21.6) & 32.2 & $54(12.5)$ & 99 (19.3) & 19.6 \\
\hline 3 & $1048(47.0)$ & $557(41.8)$ & 10.5 & $394(45.3)$ & $312(43.2)$ & 4.1 & $185(42.9)$ & $216(42.0)$ & 1.7 \\
\hline 4 & $787(35.3)$ & $376(28.2)$ & 15.2 & 339 (39) & $196(27.1)$ & 24.6 & $177(41.1)$ & $167(32.5)$ & 17.1 \\
\hline Any transfusion & $853(38.2)$ & $470(35.2)$ & 5.9 & 257 (29.6) & $181(25.1)$ & 9.9 & $136(31.6)$ & $174(33.9)$ & 4.7 \\
\hline
\end{tabular}

Year of surgery: 1 (1994) to 14 (2007). RI = number of grafts minus number of diseased coronary vessels. $S A B G$, Single arterial bypass graft; $M A B G$, multiarterial bypass graft; $S D$, standard deviation; $B S A$, body surface area; $R I$, revascularization index; $P C I$, percutaneous coronary intervention; $C A B G$, coronary artery bypass grafting; $N Y H A$, New York Heart Association. 
based on comprehensive multivariate risk adjustment using Cox regression using all covariates in Table 1, including the revascularization index (RI), regardless of their level of statistical significance. The RI was defined as the difference between the number of grafts and the number of diseased coronary systems. To confirm our findings, we next derived separate propensity score models using nonparsimonious logistic regression for each BMI group with RA-MABG considered as treatment. These models resulted in distinctly different propensity scores for the respective RA-MABG versus LITA-SABG subcohorts showing good discrimination in all BMI groups. Separate 1-to-1 (greedy), propensity-matched grafting method patient pairs were obtained within each BMI group. Patients receiving RA-MABG were always matched to the closest propensity score LITA-SABG counterparts ( $\pm 2 \%$ difference). Adequacy of matching was confirmed by calculating the standardized percent difference. ${ }^{23}$

RA-MABG versus LITA-SABG treatment effects were first quantified as the 0 - to 15 -year hazard ratios (HRs $\pm 95 \%$ confidence intervals [CIs]) using Cox proportional hazard regression models applied to all patients without adjustment (unadjusted HR), in all patients with comprehensive risk adjustment (covariate adjusted HR) for all factors in Table 1, and in propensity-matched patients (match-adjusted HR). To relax the proportional hazard assumption in the Cox regression, adjusted HRs were also calculated for multiple time segments (years) (early: 0-0.5; intermediate: 0.5-5; and late: 5-15) both for all patients and for matched-only patients. The propensity-matched survival comparison data were also used to quantify RA-MABG versus LITA-SABG treatments effects estimated as (1) the number needed to treat (NNT) to result in 1 life saved (lost) calculated at 5, 10 , and 15 years postoperatively, and (2) added years of survival at the $50 \%, 75 \%$, and $90 \%$ survival levels. Statistical analysis was conducted with SPSS version 22.0 software (SPSS Inc, Chicago, Ill).

\section{RESULTS}

The study population was composed of 6102 patients, with $2536(41.6 \%)$ all-obese, $1591(26.1 \%)$ mildly obese, and $945(15.5 \%)$ morbidly obese. Nonobese patients $(\mathrm{N}=3566,58.4 \%)$ were predominantly overweight $\left(\mathrm{BMI}=25-30 \mathrm{~kg} / \mathrm{m}^{2}: \mathrm{N}=2547[71.4 \%]\right)$ versus normal
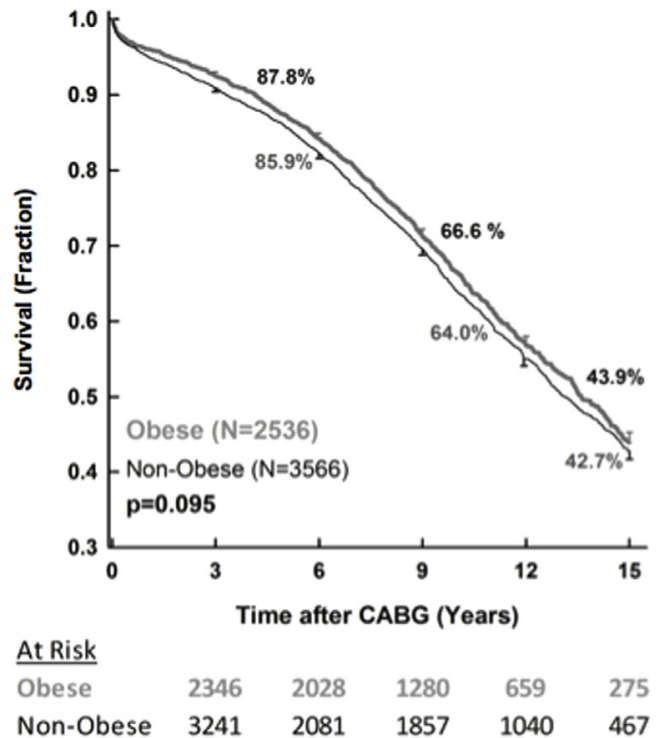

(BMI $<25 \mathrm{~kg} / \mathrm{m}^{2}: \mathrm{N}=1019$ [28.6\%]). Among the nonobese cohort, $561(15.7 \%)$ had small body habitus (body surface area $<1.7 \mathrm{~m}^{2}$ ).

RA-MABG was used in 2570 patients overall $(42.1 \%)$ and was more frequent $(48.7 \%)$ in the all-obese group (mildly obese: $45.4 \%$, morbidly obese; $54.4 \%$ ), who were younger ( $62 \pm 10$ years) compared with the nonobese group, who were older ( $66 \pm 10$ years; $37.4 \%$ RA-MABG). Patient characteristics differed substantially between RAMABG and LITA-SABG counterparts irrespective of BMI (Table 1). Briefly, for all BMI groups, the RA-MABG group tended to be younger, to have a greater RI, and to have more male subjects. Also, the frequency of RA-MABG increased substantially over the study period from approximately $20 \%$ in the 1990 s to $60 \%$ to $70 \%$ by the mid- 2000 s, as is reflected in the year of surgery variable (Table 1 ).

\section{Early, Intermediate, and Late Survival}

Overall perioperative (30-day) mortality was $1.2 \%$ (74/ $6102)$, and this was similar in the nonobese $(1.3 \%)$ and all-obese $(1.1 \%)(0.9 \%$, mildly, and $1.3 \%$, morbidly). Overall, the all-obese had a slightly and nonsignificantly $(P=.095)$ better long-term survival compared with the nonobese (Figure 1). The RA-MABG cohort was 4.2 years younger than the LITA-SABG cohort and showed substantially superior survival $(P<.001$, all $)$ at 5 years $(90.0 \%$ vs $83.7 \%), 10$ years $(70.9 \%$ vs $61.1 \%)$, and 15 years $(47.3 \%$ vs $40.3 \%$ ) (Figure 1). Kaplan-Meier analysis showed superior unadjusted 0- to 15-year RA-MABG survival compared with LITA-SABG across all BMI groups (Figure 2; all significant). Unadjusted RA-MABG versus LITA-SABG
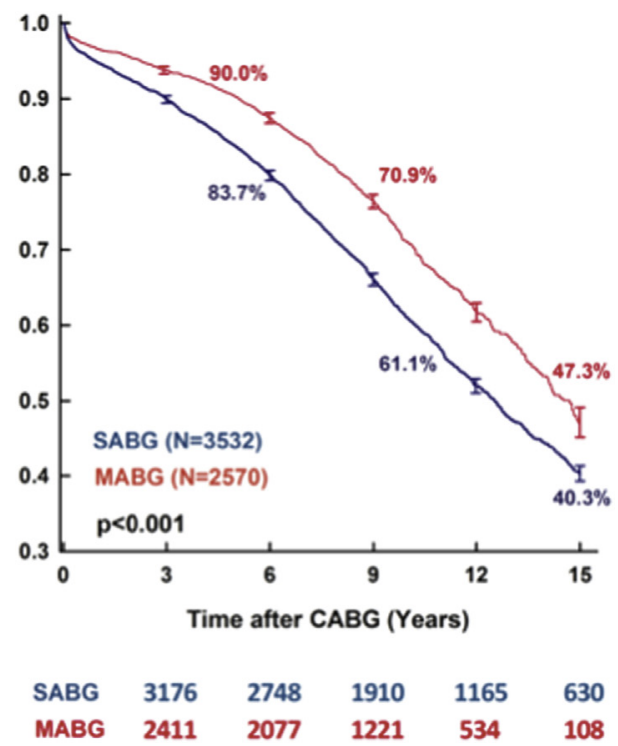

FIGURE 1. Unadjusted 15-year cumulative survival after primary CABG surgery: (left) all obese (grey line; mean age: $61.9 \pm 9.9$ years) versus all nonobese (black line; $65.8 \pm 10.5$ years) cohorts; and (right) MABG (red line; $61.7 \pm 10.2$ years) versus SABG (blue line; $66.0 \pm 10.2$ years) surgery cohorts. Error bars $= \pm 1$ standard error estimates. Percentages shown correspond to survival (\%) for each comparison group at 5, 10, and 15 years. Survival comparisons were based on log-rank test. $C A B G$, Coronary artery bypass grafting; $M A B G$, multiarterial bypass grafting; $S A B G$, single arterial bypass grafting. 

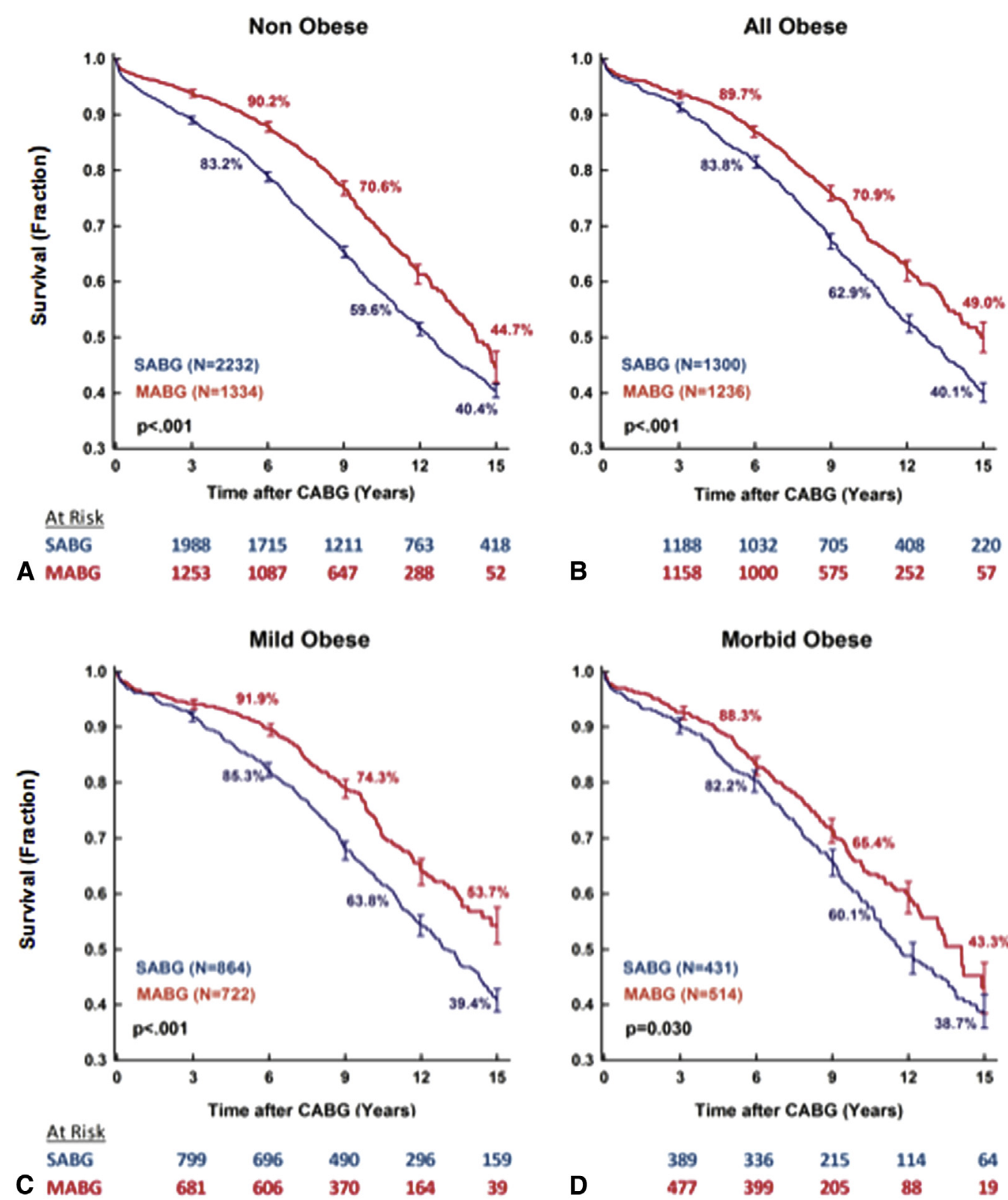

FIGURE 2. Comparison of unadjusted 15-year cumulative survival for MABG (red) versus SABG (blue) surgery cases after stratification to BMI groups: (A) nonobese, (B) all-obese, (C) mild obese, and (D) morbid obese. Error bars $= \pm 1$ standard error estimates. Percentages shown correspond to survival (\%) for each comparison group at 5, 10, and 15 years. All pairwise comparisons were significant (log rank). $C A B G$, Coronary artery bypass grafting; $M A B G$, multiarterial bypass grafting; $S A B G$, single arterial bypass grafting.

mortality HRs are summarized for each BMI group (Figure 3) and separately for early, intermediate, and late time-segments in a Forest plot in Figure 3.

\section{Risk-Adjusted Multiarterial Bypass Grafting Effects (Cox Regression)}

Comprehensive risk adjustment using Cox regression modeling was applied in all patients for each BMI group comparison to derive RA-MABG to LITA-SABG treatment effect. The covariate adjusted treatment effect results are summarized in Figure 3. In the entire 0- to 15-year period, RA-MABG compared with LITA-SABG was associated with improved survival in the nonobese cohort (HR, $0.91 ; 95 \%$ CI, 0.80-1.03) and in the all-obese cohort (HR, $0.85 ; 95 \%$ CI, 0.74-0.98). This RA-MABG survival benefit in obese patients was more pronounced in the mildly obese (HR, $0.79 ; 95 \% \mathrm{CI}, 0.66-0.96)$ than in the morbidly obese (HR, 0.88; 95\% CI, 0.69-1.13) (Figure 3).

Time-segmented, covariate-adjusted mortality HRs showed that the RA-MABG survival benefit is 

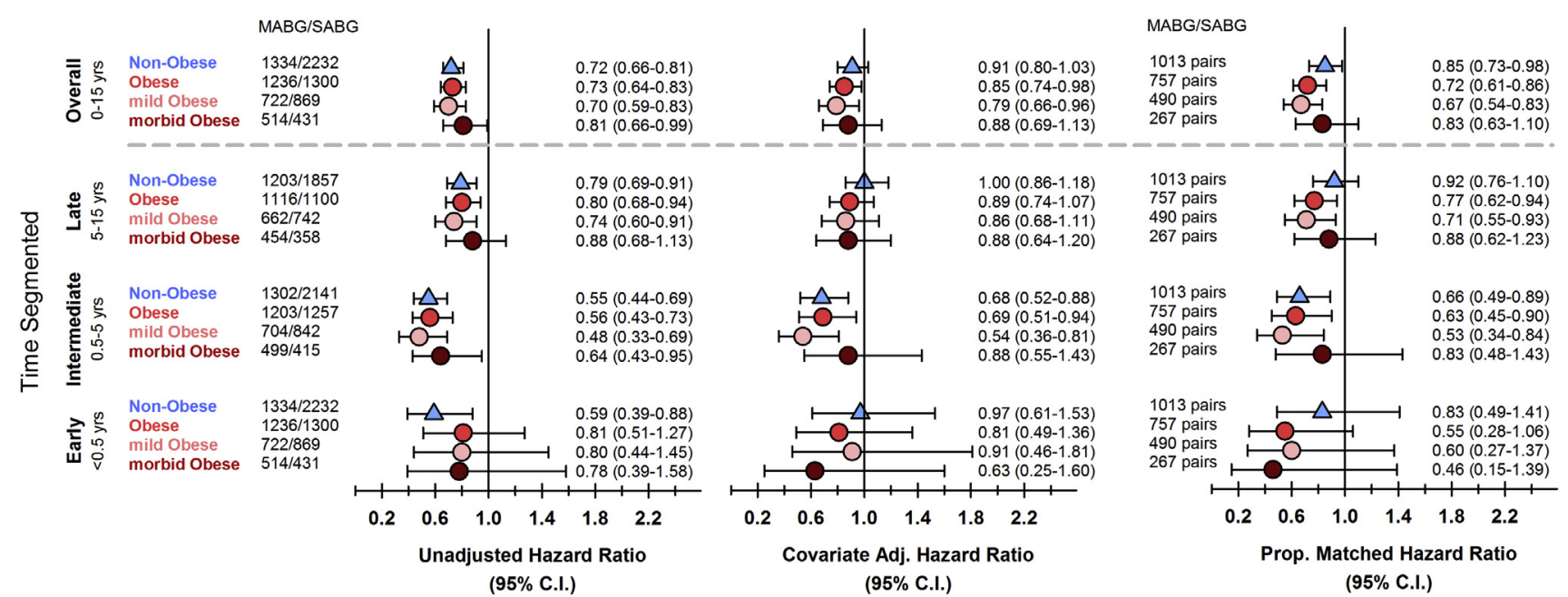

FIGURE 3. Top: Forest plot showing the time-segmented MABG versus SABG HRs ( $95 \% \mathrm{CI}$ ) for all body habitus subcohorts: unadjusted (left), covariateadjusted (middle), and propensity-matched (right) patients. Bottom: Overall and time-segmented MABG versus SABG HRs across all body habitus groups: unadjusted, covariate-adjusted, and propensity-matched results. SABG/MABG = LITA-SABG/RA-MABG; early (0-0.5 years); intermediate (0.5-5 years); late (5-15 years). *Reported HRs also adjusted. $C I$, Confidence interval; $M A B G$, multiarterial bypass grafting; $S A B G$, single arterial bypass grafting.

predominantly realized in the intermediate postoperative period (0.5-5 years) in both the all-obese (HR, 0.69; $95 \%$ $\mathrm{CI}, 0.51-0.94)$ and nonobese (HR, 0.68; 95\% CI, 0.520.88 ). Here too, the RA-MABG survival advantage was greater for the mildly obese (HR, $0.54 ; 95 \%$ CI, 0.36$0.81)$ than in the morbidly obese (HR, $0.88 ; 95 \% \mathrm{CI}$, 0.55-1.43).

Propensity matching resulted in 1013, 490, and 267 wellmatched RA-MABG and LITA-SABG pairs in the nonobese, mildly obese, and morbidly obese cohorts, respectively (Table E1). The corresponding Kaplan-Meier survival curves are shown in Figure E1. The RA-MABG versus LITA-SABG treatment effects from the propensitymatched comparisons for the overall and the timesegmented follow-up are summarized in Figure 3. The propensity-matched comparisons confirmed the results of primary covariate-adjusted analysis.

Last, for the matched pairs, we calculated the NNT with RA-MABG to save a single life at the 5-, 10- and 15-year follow-ups in each BMI category. The NNT ranged from
10 to 26 patients in the mildly obese group and from 19 to 35 patients in the morbidly obese group, whereas the effect among nonobese patients was more modest (40-67). By using the $50 \%$ survival threshold, all-obese patients were estimated to have 1.9 added years of survival $(\Delta \mathrm{t})$ with RA-MABG, whereas in nonobese patients the RAMABG added years effect was 0.3 years of additional survival. The added years benefit was more pronounced in the mildly obese $(\Delta \mathrm{t}=2.1$ years) compared with the morbidly obese $(\Delta \mathrm{t}=1.2$ years) (Figure 4$)$.

\section{DISCUSSION}

Our data indicate that RA-MABG improves long-term survival in obese patients compared with traditional LITA-SABG. This is principally driven by enhanced survival among the mildly obese in the intermediate postoperative (0.5-5 years) period. This analysis further adds to the growing body of evidence of the effectiveness and versatility of RA-MABG and so should allay reservations about using the RA as the second artery in obese patients.

\begin{tabular}{|c|c|c|c|c|c|c|c|c|c|c|c|c|}
\hline \multirow[b]{2}{*}{ No. needed to Treat (NNT) } & \multicolumn{3}{|c|}{ Non-Obese } & \multicolumn{3}{|c|}{ Obese } & \multicolumn{3}{|c|}{ Mild Obese } & \multicolumn{3}{|c|}{ Morbid Obese } \\
\hline & $\mathrm{S}_{\mathrm{MABG}}$ & $\mathrm{S}_{\mathrm{SABG}}$ & NNT & $\mathrm{S}_{\mathrm{MABG}}$ & $\mathrm{S}_{\mathrm{SABG}}$ & NNT & $\mathrm{S}_{\mathrm{MABG}}$ & $\mathrm{S}_{\mathrm{SABG}}$ & NNT & $S_{\text {MABG }}$ & $\mathrm{S}_{\mathrm{SABG}}$ & NNT \\
\hline 5 year & $88.2 \%$ & $85.7 \%$ & 40 & $88.4 \%$ & $83.9 \%$ & 22 & $89.0 \%$ & $85.1 \%$ & 26 & $86.9 \%$ & $81.4 \%$ & 18 \\
\hline 10 year & $66.8 \%$ & $64.7 \%$ & 48 & $67.3 \%$ & $62.2 \%$ & 20 & $70.7 \%$ & $64.2 \%$ & 15 & $60.6 \%$ & $57.8 \%$ & 35 \\
\hline 15 year & $43.1 \%$ & $41.6 \%$ & 67 & $46.3 \%$ & $37.9 \%$ & 12 & $49.4 \%$ & $39.6 \%$ & 10 & $40.5 \%$ & $35.2 \%$ & 19 \\
\hline Added Years $(\Delta T)$ & $T_{M A B G}$ & $\mathrm{~T}_{\mathrm{SABG}}$ & $\Delta \mathrm{T}$ & $\mathrm{T}_{\mathrm{MABG}}$ & $\mathrm{T}_{\mathrm{SABG}}$ & $\Delta \mathrm{T}$ & $\mathrm{T}_{\mathrm{MABG}}$ & $\mathrm{T}_{\mathrm{SABG}}$ & $\Delta \mathrm{T}$ & $T_{M A B G}$ & $\mathrm{~T}_{\mathrm{SABG}}$ & $\Delta T$ \\
\hline $50 \%$ survival & 13.7 & 13.4 & 0.3 & 13.7 & 11.8 & 1.9 & 14.6 & 12.5 & 2.1 & 12.4 & 11.2 & 1.2 \\
\hline $75 \%$ survival & 8.5 & 7.8 & 0.7 & 8.1 & 7.5 & 0.6 & 9 & 7.7 & 1.3 & 7.4 & 7 & 0.4 \\
\hline $90 \%$ survival & 4.1 & 3.1 & 1 & 4.3 & 3.1 & 1.2 & 4.3 & 3.1 & 1.2 & 3.8 & 2.9 & 0.9 \\
\hline
\end{tabular}

FIGURE 4. Estimated benefit of multiarterial bypass grafting versus single arterial bypass grafting in propensity-matched patients across body mass index categories: Numbers needed to treat to save 1 life and added years of life. NNT, Number needed to treat. 
Obesity is not simply a clinical challenge stemming from patients' increased size, although this in and of itself poses significant hurdles to postoperative mobility and nursing care and its incident complications. Obesity is increasingly recognized as a complex condition with significant metabolic, hemodynamic, and structural cardiovascular aberrations. Obese patients are characterized by endothelial dysfunction, increased circulating blood volume, decreased arterial resistance, pulmonary hypertension, biventricular hypertrophy, diastolic dysfunction, and increased stroke volume and sympathetic activation. ${ }^{24}$ The adipocyte, in addition to being the storage unit for excessive fat, is also an active endocrine organ secreting a variety of bioactive substances with diverse physiologic effects. ${ }^{6}$ Circulating levels of angiotensin II, C-reactive protein, fibrinogen, tumor necrosis factor- $\alpha$, and plasminogen activator inhibitor-1 are proportional to BMI. C-reactive protein, a well-known marker of chronic inflammation, has been implicated in triggering acute coronary syndromes. ${ }^{6}$ Although the specific impact of the obese milieu on radial arterial coronary grafts has not been characterized, obesity has been linked to increased RA vasoreactivity, calcification, atherogenesis, and myointimal hyperplasia when the RA is used in dialysis access. $^{22-27}$ This pathogenic nature of obesity is reflected in our obese patients' higher incidence of multiple comorbidities, such as diabetes, hypertension, and hyperlipidemia (Table 1) despite being younger than the nonobese, a finding also noted by others., ${ }^{9,21}$ Given these offsetting effects on survival, the younger higherrisk obese patients had similar unadjusted survival as the older, lower-risk nonobese patients (Figure 1). RAMABG was associated with improved unadjusted longterm survival in the overall study population (Figure 1) as well as in all BMI-based subcohorts (Figure 2). This overall RA-MABG survival advantage was driven by improved survival in the 0.5 - to 5-year postoperative period (Figure 3).

As in another report, ${ }^{21}$ RA-MABG was used more frequently among all-obese patients (48.7\%) compared with nonobese patients $(37.4 \%)$, a finding driven by our commitment to maximizing the number of arterial given the relatively young age of the obese in an effort to improve their long-term survival. Additional contributing elements to the aggressive use of RA-MABG among the obese were easier technical aspects of the typically larger RA found in the obese, avoidance of a large size mismatch between the typically large SVG of the obese and their coronary arteries, and preventing wound healing complications by minimizing dissection of the lower extremity inherent in SVG harvesting in the obese. The perioperative mortality in the all-obese was equivalent to the nonobese, a finding that was also noted by others ${ }^{10-12}$ and was equivalent across all BMI subcohorts. Given such equivalent and low perioperative mortality, CABG should not be avoided in obese patients.

Given the distinctly different pathophysiology of obese patients, the conflicting reports of the impact of obesity on operative outcomes in principally LITA-SABG ${ }^{9-13}$ and considering the diminished long-term survival of obese patients, ${ }^{8}$ the question of whether the multiarterial survival advantage seen in the general CABG population is also noted among obese patients needs further clarification. The existing data on the impact of obesity on CABG outcomes are modest and contradictory because of various methodological issues. Even less data are available on the impact of multiarterial grafting in obese patients receiving CABG. In a study of 229 obese propensity-matched BITA-MABG versus LITA-SABG study groups, Benedetto and colleagues ${ }^{20}$ reported a long-term survival advantage with the BITA grafting during a median follow-up period of 4.5 years. The BITA-MABG obese cohort showed no increased perioperative complications except for a nonstatistically significant trend for increased risk of deep sternal wound infections. In another study of 2007 obese patients, Benedetto and colleagues ${ }^{21}$ in contrast to our findings, noted equivalent 7.5-year postoperative survival between RA-MABG and LITA-SABG groups (HR, 1.05; 95\% CI, 0.80-1.38). This was true regardless of their diabetes status. In nonobese patients, a statistically significant RA-MABG associated survival advantage was noted (HR, 0.78; $95 \%$ CI, 0.65-0.94). The time course of these effects was not evaluated. There are a number of possible methodological differences between our study and that of Benedetto and colleagues $^{21}$ that may account for the alternative conclusions. Although both studies involved a relatively large number of patients, our study cohort had a higher prevalence of female patients $(21 \%-47 \%$ vs $13 \%)$, diabetes (26\%-55\% vs $18 \%)$, smoking (64\%-70\% vs $16 \%)$, chronic obstructive pulmonary disease ( $9 \%$ vs $19 \%)$, and peripheral vascular disease $(9 \%-19 \%$ vs $7 \%)$. Furthermore, our RA-MABG use was less selective, with $37.4 \%$ of the nonobese, $45.4 \%$ of the mildly obese, and $54.4 \%$ of the morbidly obese patients receiving an RA graft compared with $15 \%$ of nonobese and $20 \%$ of obese patients in Benedetto and colleagues' study. In addition, our overall RA-MABG group received 2.3 arterial grafts, whereas this number is unspecified in the other study. Finally, our propensity matching between RA-MABG and LITA-SABG cases was accomplished within each BMI group, whereas Benedetto and colleagues ${ }^{21}$ propensitymatched patients from the 2 grafting groups within the entire patient cohort (both obese and nonobese) and then used a second-order interaction between the grafting strategy and BMI, which was forced into the Cox models. The differences in the follow-up periods between the studies unlikely affected the diverse findings because the bulk of our RA-MABG survival advantage was realized in the 
intermediate postoperative time period that was well within Benedetto and colleagues' follow-up period.

Our RA-MABG survival advantage in the all-obese cohort during the overall 0 to 15 -year follow-up period (HR, 0.85 ; $95 \%$ CI, 0.74-0.98) was principally driven by a statistically significant decreased mortality HR among the mildly obese (HR, 0.79; 95\% CI, 0.66-0.96) with only a nonsignificant trend toward lower mortality among the morbidly obese (HR, 0.88; 95\% CI, 0.69-1.13) (Figure 3 and Figure E1). In light of the reported diminished 5-year survival among the morbidly obese, ${ }^{8,10,12,13}$ it is possible that this group may not live long enough to realize the RA-MABGassociated survival advantage, an effect that is most prominent within this same 5-year period. The same reasoning might hold true for underweight patients (body surface area $<1.7 \mathrm{~m}^{2}$ ), who we have also shown to have a decreased 5-year survival ${ }^{8}$ and thus likewise may not benefit from the RA-MABG survival benefit. Because these patients comprised $15.7 \%$ of the nonobese cohort, it is possible that the borderline statistically significant RA-MABG survival advantage noted in the nonobese (HR, 0.91; 95\% CI, 0.801.03) may be due to the lack of appreciable RA-MABG impact on survival among the underweight, although we did not specifically analyze this in the current study.

We are unaware of other studies focusing on the time course of any form of MABG survival advantage in the obese. Risk-adjusted, time-segmented HRs document a similar chronological pattern of the RA-MABG survival advantage in the all-obese and nonobese groups, with most of the benefit being realized in the 0.5 - to 5-year postoperative time frame (Figure 3), a pattern similar to that within the general CABG population. ${ }^{19}$ Because the survival advantage of RA-MABG versus LITA-SABG is likely driven by improved graft durability, expectedly there was no survival advantage within the first 6 months postoperatively because the SVG and RA patencies have been reported to be equivalent up to 1 year postoperatively ${ }^{28}$ and only begin to diverge thereafter. ${ }^{29}$ We hypothesize that the reason behind the mortality HR of RA-MABG versus LITA-SABG in the obese trending to unity after 5 years postoperatively may be due to the higher mortality risk, in which case these patients may die with their coronary grafts rather than because of their coronary grafts. Alternatively, the hyperinflammatory obese milieu may adversely affect arterial graft durability and thus negate any survival benefit. Graft-specific failure rates and the specific cause of death are unavailable to us, but may be helpful in clarifying the cause of this observation. The relatively early (0.5-5 year) RA-MABG survival advantage documented in this article and among the general CABG population ${ }^{19}$ appears earlier than what has been reported with BITA-MABG. ${ }^{16,19}$ Because RA-MABG does not increase the risk of sternal wound complications, the observed improved long-term survival advantage was accomplished without any increased risk of sternal wound infections inherent with BITA use ${ }^{30}$ an observation particularly important in this cohort as obesity is a known risk factor for sternal infections. ${ }^{8,10}$

We also calculated the number of patients needed to be treated (NNT) to save 1 life by preferentially adopting the RA-MBAG over the LITA-SABG strategy, as well as the number of additional survival years conferred by this strategy. Although it has been estimated that a wide adoption of MABG would result in an additional 64,000 person-life years over the course of a decade, ${ }^{31}$ we are unaware of these 2 specific metrics being previously applied to obese CABG patients. These metrics corroborate the multivariate and propensity-matched analyses showing that obese patients benefit more from RA-MABG than the nonobese patients (Figure 4). This observation supports the existence of an "obesity paradox" within the RA-MABG population, which has also been reported by others ${ }^{9}$ and warrants further analysis.

\section{Study Strengths and Limitations}

The strength of our study stems from the large size of our study group and the robust adjustments for confounding factors associated with obesity by using both propensitymatching techniques and Cox regression, with both techniques yielding corroborating results. In addition, our analysis defines the time-varying course of the RA-MABG-mediated survival advantage. Finally, as an additional guide to cardiac surgeons for the optimal grafting strategy in the obese, we provide the number of patients needed to treat to save 1 life and the number of additional years of survival associated with the RA-MABG grafting strategy, both of which are supportive of more aggressive use of RA-MABG in the obese patient.

Conversely, there are a number of weaknesses in our study. First, our study reflects a single practice experience and is retrospective in nature, and thus its conclusions may be subject to potential patient selection bias and make generalization to other settings difficult. Further, we are unable to define the cause of death, and thus we are unable to assess whether the survival advantage is due to decreased cardiovascular mortality stemming from the presumed enhanced arterial graft durability or other non-graftrelated factors. Finally, we did not separately compare RAMABG with LITA-SABG in patients with a small body habitus or in those patients who were overweight but not obese (BMI $25-30 \mathrm{~kg} / \mathrm{m}^{2}$ ).

\section{CONCLUSIONS}

Our analysis supports the aggressive use of the RA as a second arterial conduit in LITA-based CABG in the obese. Compared with the traditional LITA-SABG, this grafting strategy is associated with an improved long-term survival that is principally realized within 0.5 to 5 years postoperatively. Our results suggest that RA-MAB should be 
seriously considered by the Heart Team as the superior grafting strategy in the obese.

\section{Conflict of Interest Statement}

Authors have nothing to disclose with regard to commercial support.

\section{References}

1. Flegal JN, Carroll MD, Ogden CL, Johnson CL. Prevalence and trends in obesity among US adults, 1999-2000. JAMA. 2002;288:1723-7.

2. Lavie CJ, Milani RV. Obesity and cardiovascular disease: the Hippocrates paradox? J Am Coll Cardiol. 2003;42:677-9.

3. Manson JE, Bassuk SS. Obesity in the United States: a fresh look at its high toll. JAMA. 2003;289:229-30.

4. Lavie CJ, Milani RV, Ventura HO. Obesity and cardiovascular disease: risk factor, paradox and impact of weight loss. J Am Coll Cardiol. 2009;53:1925-32.

5. Zacharias A, Schwann TA, Riordan CJ, Durham SJ, Shah AS, Habib RH. Obesity and risk of new onset atrial fibrillation after cardiac surgery. Circulation. 2005; 112:3247-55.

6. Poirier P, Giles TD, Bray GA, Hong Y, Stern JS, Pi-Sunyer X, et al. Obesity and cardiovascular disease: pathophysiology, evaluation and effect of weight loss. Circulation. 2006;113:898-918.

7. Schwann TA, Tatoulis J, Puskas J, Bonnell MR, Taggart D, Kurlansky P, et al. Worldwide trends in multi-arterial CABG surgery 2004-2016: a tale of two continents. Semin Thorac Cardiovasc Surg. 2017;29:273-80.

8. Habib RH, Zacharias A, Schwann TA, Riordan CJ, Durham SJ, Shah A. Effects of obesity and small body size on operative and long term outcomes of coronary artery bypass surgery: a propensity matched analysis. Ann Thorac Surg. 2005;79: 1976-86.

9. Benedetto U, Danese C, Codispoti M. Obesity paradox in coronary artery bypass grafting: myth or reality. J Thorac Cardiovasc Surg. 2014;147:1517-23.

10. Stamou SC, Nussbaum M, Stiegel RM, Reames MK, Skipper ER, Robicsek F, et al. Effect of body mass index on outcomes after cardiac surgery; is there an obesity paradox. Ann Thorac Surg. 2011;91:42-7.

11. Le-Bert G, Santana O, Pineda AM, Zamora C, Lamas GA, Lamelas J. The obesity paradox in elderly obese patients undergoing coronary artery bypass surgery. Interact Cardiovasc Thorac Surg. 2011;13:124-7.

12. van Straten AHM, Bramer S, Hamad S, van Zundert AJA, Martens EJ, Schonberger J, et al. Effect of body mass index on early and late mortality after coronary artery bypass grafting. Ann Thorac Surg. 2010;89:30-7.

13. Schwann TA, Habib RH, Zacharias A, Parenteau GL, Riordan CJ, Durham SJ, et al. Effects of body size on operative, intermediate and long term outcomes after coronary artery bypass surgery. Ann Thorac Surg. 2001;71:521-31.

14. Locker C, Schaff HV, Dearani JA, Joyce LD, Park SJ, Burkhart HM, et al. Multiple arterial grafts improve late survival of patients undergoing coronary artery bypass graft surgery. Circulation. 2012;126:1023-30.

15. Zacharias A, Habib RH, Schwann TA, Riordan CJ, Durham SJ, Shah A. Improved survival with radial artery versus vein conduits in coronary bypass surgery with left internal thoracic artery to left anterior descending artery grafting. Circulation. 2004;109:1489-96.
16. Lytle BW, Blackstone EH, Sabik JF, Houghtaling P, Loop FD, Cosgrove DM. The effect of bilateral internal thoracic artery grafting on survival during 20 postoperative years. Ann Thorac Surg. 2004;78:2005-12.

17. Tranbaugh RF, Dimitrova KR, Friedmann P, Geller CM, Harris LJ, Stelzer P, et al. Radial artery conduits improve long-term survival after coronary artery bypass grafting. Ann Thorac Surg. 2010;90:1165-72.

18. Kurlansky PA, Traad EA, Dorman MJ, Galbut DL, Zucker M, Ebra G. Thirtyyear follow-up defines survival benefit for second internal mammary artery in propensity-matched groups. Ann Thorac Surg. 2010;90:10-108.

19. Schwann TA, Tranbaugh RF, Dimitrova KR, Engoren MC, Kabour A Hoffman DM, et al. Time varying survival benefit of radial artery versus vein grafting; a multi institutional study. Ann Thorac Surg. 2014;97:1328-34.

20. Benedetto U, Montecalvo A, Kattach H, Amrani M, Raja SG. Impact of the second internal thoracic artery on short- and long-term outcomes in obese patients: a propensity score matched analysis. J Thorac Cardiovasc Surg. 2015;149:841-7.

21. Benedetto U, Caputo M, Zakkar M, Davies A, Gibbison B, Bryan A, et al. The effect of obesity on survival in patients undergoing coronary artery bypass graft surgery who receive a radial artery. Eur J Cardiothorac Surg. 2017;51:376-81.

22. Schwann TA, Al-Shaar L, Engoren M, Habib RH. Late effects of radial artery versus saphenous vein grafting for multivessel coronary bypass surgery in diabetics - a propensity matched analysis. Eur J Cardiothorac Surg. 2013;44: 701-10.

23. Austin PC. Using the standardized difference to compare the prevalence of a binary variable between two groups in observational research. Commun Stat Simul Comput. 2009;38:1228-34.

24. Lavie CJ, McAuley PA, Church TS, Milani RV, Blair SN. Obesity and cardiovascular disease. Implications regarding fitness, fatness and severity in the obesity paradox. J Am Coll Cardiol. 2014;63:1345-54.

25. Kim JK, Jeong JH, Song YR, Kim HJ, Lee WY, Kim KY, et al. Obesity-related decrease in intraoperative blood flow is associated with maturation failure of radiocephalicarteriovenous fistula. J Vasc Surg. 2015;62:1010-7.

26. Lind L, Zethelius B, Sundbom M, Eden Engstrom B, Karlsson FA. Vasoreactivity is rapidly improved in obese subjects after gastric bypass surgery. Int J Obes. 2009;33:1390-5.

27. Ozkan S, Akay TH, Gultekin B, Aslim E, Arslan A, Ozdemir BH, et al. Atherosclerosis of radial and internal thoracic arteries used in coronary bypass: atherosclerosis of arterial grafts. J Card Surg. 2007;22:385-9.

28. Goldman S, Sethi GK, Holman W, Thai H, McFalls E, Ward HB, et al. Radial artery grafts vs saphenous vein grafts in coronary artery bypass surgery: a randomized trial. JAMA. 2011;305:167-74.

29. Deb S, Cohen EA, Singh SK, Une D, Laupacis A, Fremes SE, for the RAPS Investigators. Radial artery and saphenous vein patency more than 5 years after coronary artery bypass surgery. J Am Coll Cardiol. 2012;60:28-35.

30. Taggart DP, Altman DG, Gray AM, Lees B, Gerry S, Benedetto U, et al; for the ART Investigators. Randomized trial of bilateral versus internal-thoracic artery grafts. N Engl J Med. 2016;375:2540-9.

31. Tranbaugh RF, Lucido DJ, Dimitrova KR, Hoffman DM, Geller CM, Dincheva GR, et al. Multiple arterial bypass grafting should be routine. J Thorac Cardiovasc Surg. 2015;150:1537-44.

Key Words: multiarterial CABG, obesity, body mass index 

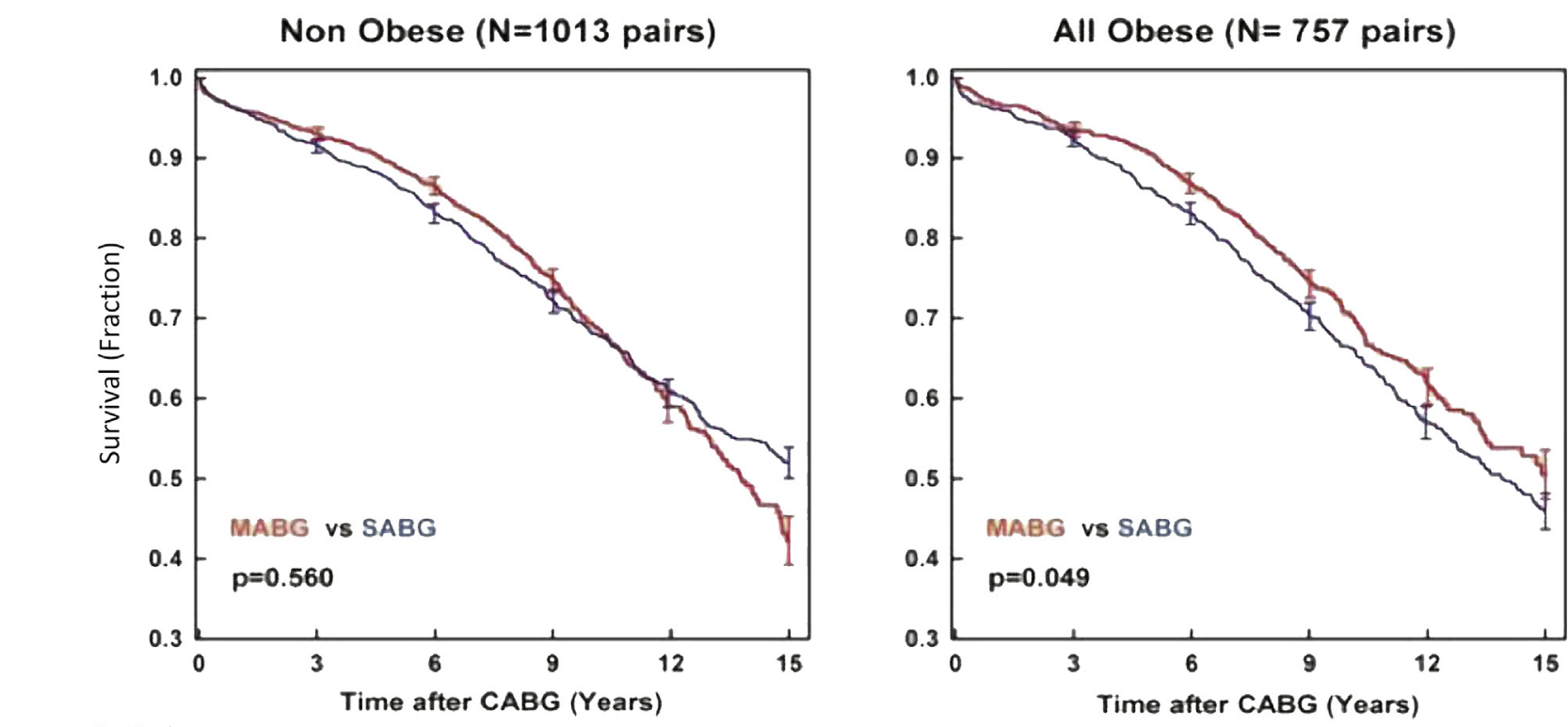

$\begin{array}{lllllll} & \text { At Risk } & & & & & \\ & \text { A SABG } & 927 & 807 & 555 & 350 & 213 \\ \text { A } & \text { MABG } & 942 & 807 & 494 & 232 & 38\end{array}$

$\begin{array}{cccccc} & 699 & 608 & 412 & 242 & 146 \\ \text { B } & 708 & 607 & 372 & 183 & 41\end{array}$
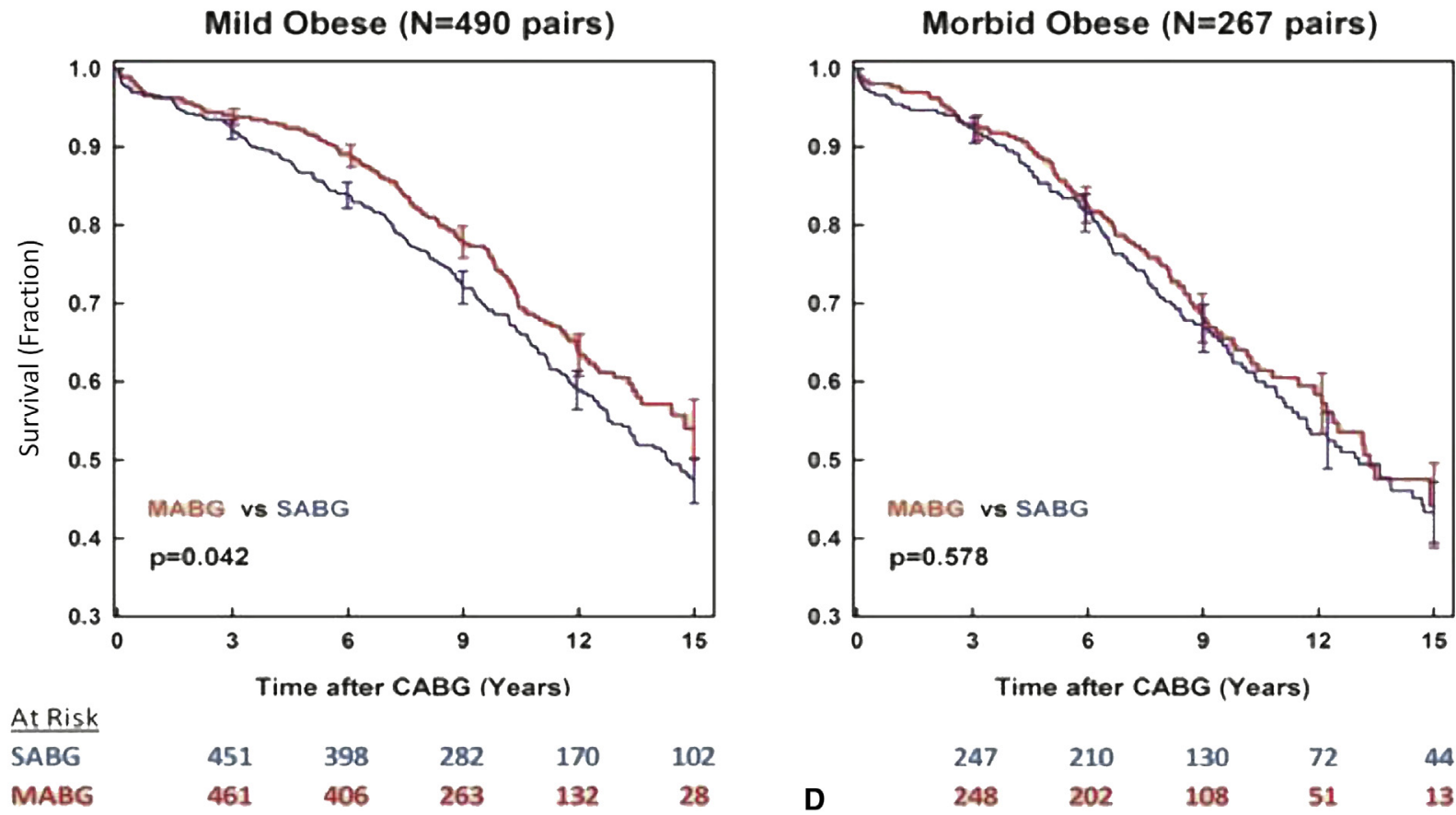

At Risk

\begin{tabular}{llllll}
\hline SABG & 451 & 398 & 282 & 170 & 102
\end{tabular}

C MABG

$\begin{array}{lllll}461 & 406 & 263 & 132 & 28\end{array}$

D

FIGURE E1. Comparison of 15-year cumulative survival shown for propensity-matched MABG (red) versus SABG (blue) surgery cases within each BMI group: A, Nonobese (1013 pairs). B, All-obese (757 pairs). C, Mild obese (490 pairs). D, Morbid obese (267 pairs). Error bars $= \pm 1$ standard error estimate. $C A B G$, Coronary artery bypass grafting; $M A B G$, multiarterial bypass grafting; $S A B G$, single arterial bypass grafting. 
TABLE E1. Demographic, comorbidity, and operative data in propensity-matched single arterial bypass graft versus multiarterial bypass graft cases stratified to nonobese, mild obese, and morbid obese

\begin{tabular}{|c|c|c|c|c|c|c|c|c|c|}
\hline \multirow[b]{2}{*}{ Continuous variables } & \multicolumn{3}{|c|}{ Nonobese ( $N=1013$ pairs) } & \multicolumn{3}{|c|}{ Mild obese ( $N=490$ pairs) } & \multicolumn{3}{|c|}{ Morbid obese ( $N=267$ pairs) } \\
\hline & $\begin{array}{c}\text { SABG } \\
\left(\begin{array}{l}N=1013) \\
\text { Mean } \pm \text { SD }\end{array}\right.\end{array}$ & $\begin{array}{c}\text { MABG } \\
\left(\begin{array}{l}N=1013) \\
\text { Mean } \pm \text { SD }\end{array}\right.\end{array}$ & $\%$ Diff & $\begin{array}{c}\text { SABG } \\
(\mathrm{N}=490) \\
\text { Mean } \pm \text { SD }\end{array}$ & $\begin{array}{c}\text { MABG } \\
(\mathrm{N}=490) \\
\text { Mean } \pm \text { SD }\end{array}$ & $\%$ Diff & $\begin{array}{c}\text { SABG } \\
(\mathbf{N}=267) \\
\text { Mean } \pm \text { SD }\end{array}$ & $\begin{array}{c}\text { MABG } \\
(\mathbf{N}=\mathbf{2 6 7 )} \\
\text { Mean } \pm \text { SD }\end{array}$ & $\%$ Diff \\
\hline Age (y) & $64.3 \pm 10.5$ & $64.4 \pm 10.2$ & 1.6 & $62.2 \pm 9.5$ & $62.5 \pm 9.7$ & 2.9 & $60.3 \pm 9.5$ & $59.9 \pm 9.4$ & 4.7 \\
\hline $\operatorname{BSA}\left(\mathrm{m}^{2}\right)$ & $1.93 \pm 0.19$ & $1.93 \pm 0.19$ & 1.2 & $2.13 \pm 0.18$ & $2.13 \pm 0.18$ & 4.1 & $2.30 \pm 0.23$ & $2.30 \pm 0.23$ & 1.0 \\
\hline Ejection fraction & $49.3 \pm 11.3$ & $49.4 \pm 10.4$ & 1.1 & $48.7 \pm 11.5$ & $49.6 \pm 10.5$ & 7.8 & $49.3 \pm 10.9$ & $49.3 \pm 9.2$ & 0.1 \\
\hline Perfusion time (min) & $81.0 \pm 31.0$ & $81.0 \pm 31.0$ & 1.6 & $85 \pm 30$ & $82 \pm 33$ & 10.1 & $82 \pm 34$ & $82 \pm 28$ & 1.6 \\
\hline Crossclamp time (min) & $51.0 \pm 21.0$ & $51.0 \pm 22.0$ & 0.4 & $51 \pm 20$ & $50 \pm 21$ & 8.3 & $51 \pm 23$ & $51 \pm 20$ & 3.4 \\
\hline RI & $0.66 \pm 0.74$ & $0.69 \pm 0.70$ & 4.7 & $0.65 \pm 0.72$ & $0.64 \pm 0.72$ & 1.4 & $0.58 \pm 0.74$ & $0.55 \pm 0.77$ & 3.5 \\
\hline No. of grafts & $3.46 \pm 0.85$ & $3.48 \pm 0.83$ & 2.9 & $3.46 \pm 0.86$ & $3.42 \pm 0.87$ & 5.2 & $3.37 \pm 0.9$ & $3.35 \pm 0.86$ & 2.6 \\
\hline $\begin{array}{l}\text { No. of distal arterial } \\
\text { anastamoses }\end{array}$ & $1 \pm 0$ & $2.23 \pm 0.50$ & 345.2 & $1 \pm 0$ & $2.22 \pm 0.48$ & 360.0 & $1 \pm 0$ & $2.19 \pm 0.47$ & 362.2 \\
\hline $\begin{array}{l}\text { No. of distal vein } \\
\text { anastmoses }\end{array}$ & $2.46 \pm 0.85$ & $1.25 \pm 0.82$ & 143.6 & $2.46 \pm 0.86$ & $1.19 \pm 0.86$ & 147.5 & $2.37 \pm 0.9$ & $1.15 \pm 0.87$ & 137.5 \\
\hline Year of surgery $(1-14)^{a}$ & $6.44 \pm 3.9$ & $8.48 \pm 2.98$ & 58.8 & $6.19 \pm 3.88$ & $8.16 \pm 3.03$ & 56.6 & $6.71 \pm 3.86$ & $8.67 \pm 3.07$ & 56.0 \\
\hline Categoric variables & Counts $(\%)$ & Counts $(\%)$ & $\%$ Diff & Counts $(\%)$ & Counts (\%) & $\%$ Diff & Counts $(\%)$ & Counts $(\%)$ & $\%$ Diff \\
\hline Male & $765(75.5)$ & $763(75.3)$ & 0.5 & $353(72.0)$ & $352(71.8)$ & 0.4 & $155(58.0)$ & $149(55.8)$ & 4.3 \\
\hline Smoking & $705(69.6)$ & $695(68.6)$ & 2.1 & $315(64.30)$ & $320(65.3)$ & 2.0 & $176(65.9)$ & $175(65.5)$ & 0.8 \\
\hline Diabetes & $260(25.7)$ & 277 (27.3) & 3.7 & $200(40.8)$ & $205(41.8)$ & 2.0 & 138 (51.7) & $145(54.3)$ & 5.0 \\
\hline $\begin{array}{l}\text { Insulin dependence } \\
\text { Hypercholesterolemia }\end{array}$ & $\begin{array}{c}75(7.4) \\
719(71.0)\end{array}$ & $\begin{array}{c}78(7.7) \\
713(70.4)\end{array}$ & $\begin{array}{l}1.3 \\
1.3\end{array}$ & $360(73.5)$ & $\begin{array}{r}54(11.0) \\
357(72.9)\end{array}$ & $\begin{array}{l}1.4 \\
1.4\end{array}$ & $201(75.3)$ & $203(76.0)$ & $\begin{array}{l}0.0 \\
1.7\end{array}$ \\
\hline Hypertension & $785(77.5)$ & $785(77.5)$ & 0.0 & $408(83.3)$ & $408(83.3)$ & 0.0 & $231(86.5)$ & $229(85.8)$ & 2.3 \\
\hline Peripheral vascular disease & $137(13.5)$ & $135(13.3)$ & 0.6 & $54(11.0)$ & $54(11.0)$ & 0.0 & $32(12.0)$ & $33(12.4)$ & 1.2 \\
\hline Cerebrovascular disease & $213(21.0)$ & $204(20.1)$ & 2.2 & 96 (19.6) & $104(21.2)$ & 4.1 & $46(17.2)$ & $54(20.2)$ & 7.9 \\
\hline Cerebrovascular accident & $74(7.3)$ & $73(7.2)$ & 0.4 & $25(5.1)$ & $34(7.0)$ & 9.1 & $13(4.9)$ & $17(6.4)$ & 7.7 \\
\hline Chronic lung disease & $197(19.5)$ & $191(18.9)$ & 1.5 & $86(17.6)$ & $74(15.1)$ & 6.8 & $56(21.0)$ & $57(21.4)$ & 0.9 \\
\hline Myocardial infarction & $551(54.4)$ & $545(53.8)$ & 1.1 & $270(55.1)$ & $260(53.1)$ & 3.9 & $141(52.8)$ & $149(55.8)$ & 5.7 \\
\hline Congestive heart failure & $82(8.1)$ & $71(7.0)$ & 4.5 & $53(10.8)$ & $50(10.2)$ & 2.2 & $39(14.6)$ & $33(12.4)$ & 6.9 \\
\hline 2-vessel disease & $184(18.2)$ & $191(18.9)$ & 1.8 & $87(17.8)$ & $104(21.2)$ & 8.9 & $55(20.6)$ & $50(18.7)$ & 4.8 \\
\hline 3-vessel disease & $810(80.0)$ & $804(79.4)$ & 1.5 & $397(81.0)$ & $380(77.6)$ & 8.7 & $209(78.3)$ & $213(79.8)$ & 3.7 \\
\hline Multivessel disease & $994(98.1)$ & 995 (98.2) & 0.9 & $484(98.8)$ & $484(98.8)$ & 0.0 & $264(98.9)$ & $263(98.5)$ & 4.4 \\
\hline Left main disease & $250(24.7)$ & 239 (23.6) & 2.5 & $103(21.0)$ & $102(20.8)$ & 0.5 & 47 (17.6) & 47 (17.6) & 0.0 \\
\hline \multicolumn{10}{|l|}{ PCI } \\
\hline Balloon angioplasty & $74(7.3)$ & $79(7.8)$ & 2.1 & $37(7.6)$ & $35(7.1)$ & 1.7 & $22(8.2)$ & $19(7.1)$ & 4.7 \\
\hline Stent & $114(11.3)$ & $102(10.1)$ & 4.1 & $58(11.8)$ & $60(12.2)$ & 1.3 & $28(10.5)$ & $33(12.4)$ & 6.4 \\
\hline Arrhythmia & $71(7.0)$ & $70(6.9)$ & 0.4 & $38(7.8)$ & $28(5.7)$ & 9.0 & $21(7.9)$ & $15(5.6)$ & 9.9 \\
\hline Unstable & $309(30.5)$ & $312(30.8)$ & 0.6 & $164(33.5)$ & $165(33.7)$ & 0.4 & $92(34.5)$ & $88(33.0)$ & 3.0 \\
\hline Emergency & $60(5.9)$ & $61(6.0)$ & 0.5 & $25(5.1)$ & $28(5.7)$ & 3.2 & $12(4.5)$ & $14(5.2)$ & 4.1 \\
\hline CABG + other surgery & $89(8.8)$ & $84(8.3)$ & 1.9 & $48(9.8)$ & $50(10.2)$ & 1.5 & $18(6.7)$ & $24(9.0)$ & 9.6 \\
\hline \multicolumn{10}{|l|}{ NYHA class } \\
\hline 1 & $71(7.0)$ & $66(6.5)$ & 2.2 & $32(6.5)$ & $33(6.7)$ & 0.9 & $9(3.4)$ & $9(3.4)$ & 0.0 \\
\hline 2 & 195 (19.3) & $193(19.1)$ & 0.5 & 72 (14.7) & $71(14.5)$ & 0.6 & $40(15.0)$ & $40(15.0)$ & 0.0 \\
\hline 3 & $430(42.5)$ & $432(42.7)$ & 0.4 & $221(45.1)$ & $234(47.8)$ & 5.0 & 119 (44.6) & $119(45.0)$ & 0.0 \\
\hline 4 & $317(31.3)$ & $322(31.8)$ & 1.0 & 165 (33.7) & $152(31.0)$ & 5.5 & $99(37.1)$ & 99 (37) & 0.0 \\
\hline Any transfusion & $367(36.2)$ & $356(35.1)$ & 2.2 & $127(25.9)$ & $132(26.9)$ & 2.3 & $83(31.1)$ & $86(32.0)$ & 2.3 \\
\hline
\end{tabular}

Year of surgery: 1 (1994) to 14 (2007). RI = number of grafts minus number of diseased vessels. $S A B G$, Single arterial bypass graft; $M A B G$, multiarterial bypass graft; $S D$, standard deviation; $B S A$, body surface area; $R I$, revascularization index; $P C I$, percutaneous coronary intervention; $C A B G$, coronary artery bypass grafting; $N Y H A$, New York Heart Association. 